\title{
Corpo e política: notas sobre a educação do corpo ${ }^{1}$
}

Body and politics: notes on body education

Cuerpo y política: notas sobre la educación del cuerpo

Fabio Zoboli ${ }^{\mathrm{I}}$, Cristiano Mezzaroba ${ }^{\mathrm{II}}$

\begin{abstract}
Resumo
O ensaio objetiva refletir em torno do pressuposto de que o corpo só pode ser objeto de estudo da Educação a partir de suas práticas que o tomam como campo empírico - investigar o corpo em detrimento delas significa reduzi-lo a sua dimensão física. Pensar o corpo sob a égide de suas práticas significa reflexionar sobre a política que funda os processos de incorporação de sentidos sociais dos usos dos corpos. Compreender os corpos via leitura histórica das políticas que as fixaram e legitimaram é fundamental para desnaturalizar o naturalizado das tramas sociais relacionadas ao comportamento dos sujeitos e seus corpos.
\end{abstract}

Palavras-chave: Educação; Corpo; Política

\begin{abstract}
The essay aims to reflect on the assumption that the body can only be the object of Education study from its practices that understand it as an empirical field - investigating the body to the detriment of them means reducing it to its physical dimension. To think about body under the aegis of its practices means to reflect on the politics that ground the processes of incorporation of social meanings of the uses of the bodies. Understanding bodies through a historical perspective of the politics that established and legitimized them it is fundamental to denaturalize the naturalized social frames related to the behavior of subjects and their bodies.
\end{abstract}

Keywords: Education; Body; Politics

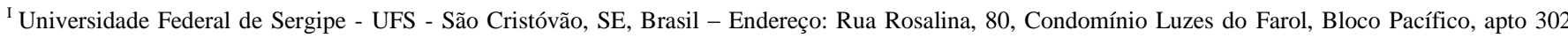
Farolândia , Aracaju - SE, CEP: 49032-150 - e-mail: zobolito@gmail.com

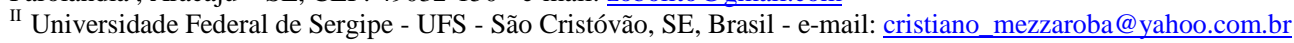

\footnotetext{
${ }^{1}$ Uma versão reduzida deste texto (ZOBOLI, 2018) foi publicada como capítulo no livro "Diálogos interdisciplinares e temas emergentes na produção do conhecimento em Educação" organizado por Ana Cláudia da Silva Rodrigues e José Leonardo Rolim Severo. Livro este que apresenta as palestras proferidas no "XXIV Encontro de pesquisadores em educação do Nordeste (EPEN)" de 2018 realizado em João Pessoa-PB.
} 


\section{Resúmen}

El texto tiene como objetivo reflejar en torno al la presuposición de que el cuerpo sólo puede ser objeto de estudio de la Educación a partir de sus prácticas que lo toman como campo empírico - investigar el cuerpo en detrimento de ellas significa reducirlo a su dimensión física. Pensar el cuerpo bajo la égida de sus prácticas significa reflexionar sobre la política que funda los procesos de incorporación de sentidos sociales de los usos de los cuerpos. Comprender los cuerpos vía lectura histórica de las políticas que las fijaron y legitimaron es fundamental para desnaturalizar el naturalizado de las tramas sociales relacionadas al comportamiento de los sujetos y sus cuerpos.

Palavras clave: Educación; Cuerpo; Política

\section{Introdução}

Entendemos que o corpo não existe fora da política, fora da palavra. Dessa forma, a política é assunto de seres falantes. Dizer isso é o mesmo que dizer que a política é assunto de corpos falantes, porque eles não falariam se não tivessem um corpo. Ou ainda, se eles tivessem apenas corpos e não falassem, eles não precisariam de política (MILNER, 2013). O ser humano é o único animal falante ${ }^{2}$, o ser humano é o único animal político.

Milner (2013, p. 18) sustenta o pressuposto de que "[...] la política se reduce a técnicas del cuerpo". Por técnicas do corpo, ou "técnicas corporais", Mauss (2015, p. 385) entende "[...] as maneiras como os homens, de sociedade a sociedade, de uma forma tradicional, sabem servir-se de seu corpo".

Nas técnicas do corpo culturalmente transmitidas estão inscritos discursos políticos e sentidos estéticos, assim, educar um corpo é transmitir a ele modos políticos e sentidos estéticos. Podemos visualizar isso quando pensamos nos modos de andar, de sentar-se à mesa, na maneira como nossos corpos se apropriam de determinados espaços da casa para fazer uma ou outra coisa, na forma como nos vestimos ou utilizamos adornos corporais, nas nossas práticas de higiene, nas manifestações corporais (danças, jogos, esportes e lutas), entre tantos outros exemplos que revelam padrões incorporados e naturalizados nos usos políticos do corpo. Como afirma Beatriz Preciado (2014), a arquitetura dos usos do corpo é política, e é ela que organiza as práticas e as qualifica como: públicas ou privadas, institucionais ou domésticas, sociais ou íntimas.

Com Mauss (2015) aprendemos a importância do social, enquanto exterioridade, na constituição de nossos corpos, de nossa subjetividade ${ }^{3}$, a influência daquilo que "vem de fora" e impacta "dentro" de cada sujeito: "É graças à sociedade que há uma intervenção da consciência. Não é graças à inconsciência que há uma intervenção da sociedade. É graças à sociedade que há segurança e presteza nos movimentos, domínio do consciente sobre a emoção e o inconsciente". (MAUSS, 2015, p. 419).

\footnotetext{
${ }^{2}$ Aristóteles se refere ao homem como ser político, pois é um animal que fala. Por isso as expressões de seres falantes nesse texto.

${ }^{3}$ Velho (2006), abordando sobre a clássica discussão quanto à identidade social e individual, afirma que a subjetividade é sempre produzida pela sociedade: "Assim, seja a interação, a sociedade ou a cultura, a subjetividade - o interno - é produzida, condicionada, fabricada pelo externo. O indivíduo ou o self, dependendo da vertente, é essencialmente social." (VELHO, 2006, p. 21).
} 
Bourdieu (2011), por sua vez, ao considerar que o corpo é um depósito de incorporações das estruturas objetivas (estruturas econômicas e sociais), elege nessa materialidade corpórea uma forma de ser rascunho para os padrões sociais e culturais:

\begin{abstract}
As injunções sociais mais sérias se dirigem ao corpo e não ao intelecto, o primeiro tratado como rascunho. $\mathrm{O}$ essencial da aprendizagem da masculinidade e da feminilidade tende a inscrever a diferença entre os sexos nos corpos (sobretudo por meio do vestuário), sob a forma de maneiras de andar, de falar, de se comportar, de dirigir o olhar, de sentar-se etc. E os ritos de instituição constituem apenas o limite de todas as ações explícitas pelas quais os grupos trabalham para inculcar os limites sociais, ou, o que dá no mesmo, as classificações sociais (por exemplo, a divisão masculino/feminino), a naturalizá-las sob a forma de divisões nos corpos, as hexis corporais, as disposições, das quais se sabe serem tão duráveis como as inscrições indeléveis da tatuagem, e os princípios coletivos de visão e de divisão. Tanto na ação pedagógica cotidiana ("fica direito", "segure a faca com a mão direita") como nos ritos de instituição, essa ação psicossomática se exerce muitas vezes por meio da emoção e do sofrimento, psicológico ou até físico, mormente aquele que se inflige pela inscrição de signos distintivos, mutilações, escarificações ou tatuagens, na própria superfície dos corpos (BOURDIEU, 2011, p. 172-173).
\end{abstract}

Frente a essas primeiras considerações, temos como objetivo refletir, em forma de ensaio, o pressuposto de que o corpo só pode ser objeto de estudo da Educação a partir de suas práticas que o tomam como campo empírico sob a forma de fenômenos recortados destas práticas culturais humanas (que aqui chamaremos de habitus, de técnicas e hexis corporal). Interpelar o corpo a partir delas implica estudá-las sob a mirada da política nas quais elas estão inscritas, como sugere Galak (2014, p. 356): "Investigar o corpo significa refazer os caminhos pelos quais a incorporação dos sentidos analisados transitou".

A fim de apreender estas questões organizamos o texto a partir de duas partes: em um primeiro momento dissertamos, de forma esparsa, o corpo enquanto objeto de estudo que só pode ser interpelado a partir de suas práticas, do contrário o estamos reduzindo à sua biologia ou materialidade física. Na segunda e última parte apresentamos o corpo tensionando a política como fundante no processo de incorporação e naturalização de sentidos sociais das técnicas corporais. Ao final, nas considerações finais, tecemos mais alguns comentários quanto às implicações da política na educação do corpo.

\title{
20 corpo enquanto objeto de pesquisa na educação
}

Quando somos convidados a escrever sobre corpo ou nos propomos a dissertar sobre sua inserção no âmbito das pesquisas do campo da Educação - e das ciências sociais e humanas de modo geral - nos deparamos com o desconforto de não conseguir abarcar a sua totalidade. Para nos privarmos desse "mal-estar" temos que 
reconhecer que o todo do corpo não pode ser apreendido. Isso só é possível quando o reduzimos à sua condição de organismo biológico ${ }^{4}$ à sua condição material, enquanto organismo físico.

Desta forma, na Educação não se pesquisam corpos, mas sim o corpo no contexto de suas práticas sociais no interior de dinâmicas socioculturais. Pretender investigar "corpos" em detrimento de suas práticas significa reduzi-lo ao seu lado natural e físico, é colocar sua biologia à frente do social incorporado, é confundir o natural com o naturalizado (GALAK, 2014). Ainda sobre tal constatação, Crisorio (2015, p. 34) expõe a seguinte reflexão: "Nosotros utilizamos la expresión prácticas corporales para significar un cuerpo que nunca puede separarse de su práctica, en el que nunca puede aislarse algo como un sustrato natural o un principio sustancial, sea físico o biológico".

Assim, o corpo como objeto de pesquisa da Educação só pode ser abordado enquanto superfície de inscrição de signos que são capturadas via práticas que lhes dão o sentido: "Volver el cuerpo un objeto de estudio es darle palabra a ese lenguage, es hacer hablar los sentidos coyunturales outorgados a las maneras como se conciben los sujetos y la política" (GALAK, 2014, p. 357).

Aqui, como pesquisadores do campo da Educação, podemos pensar numa série de práticas que a modernidade fez uso para incorporar e naturalizar sentidos via educação dos corpos para seus usos políticos: todas as práticas educativas eugênicas e higiênicas legitimadas pela biologia moderna que a partir dos séculos XVII e XVIII controlaram e disciplinaram os corpos a fim de modelar a normalidade e a ordem.

E não só esta gama de práticas historicamente construídas e legitimadas pela Educação como projeto da modernidade, mas também as que estão na pauta das políticas públicas educacionais nesta segunda década do século XXI: a diversidade sexual e de gênero, a manipulação e potencialização do corpo via tecnologia, as políticas de respeito à pluralidade étnica, os usos do corpo na era digital, os aspectos da multiculturalidade e as implicações nas questões corporais, entre tantas outras. Todas elas podem e devem ser objetos de nossas pesquisas a fim de refletir sobre os discursos que se incorporam e se naturalizam nos corpos via educação, permitindo a compreensão mais ampla, a partir daquilo que Mauss (2015) denominou de estudo sociopsicobiológico, numa perspectiva interdisciplinar que contemple vários campos do conhecimento.

No entanto, além do recorte da prática sob a qual vamos investigar o corpo, faz-se necessário significar este corpo e esta prática a partir de um viés epistemológico e metodológico que o categorize e dê sentido. Isso significa afirmar que "o 'corpo' é uma linha de pesquisa e não uma realidade em si”" (LE BRETON, 2009, p. 33). Para Bártolo (2007), onde se encontra um corpo dever-se-á encontrar também uma rede de relações instrumentais, uma série em funcionamento, de operadores epistêmicos, uma lógica de produção de sentidos, de um determinado sentido legitimador da rede de relações, do funcionamento dos operadores, do próprio procedimento das lógicas produtivas. O corpo enquanto objeto de pesquisa da Educação é algo a ser significado, o que é corroborado por Le

\footnotetext{
${ }^{4}$ A medicina tem a pretensão de considerar que tem certo domínio sobre essa totalidade corporal, mas pra chegar a isso, peca por fragmentar/setorizar/separar essa totalidade em especialidades médicas, dificultando a possibilidade da compreensão holística do corpo humano, como aponta, por exemplo, Luz (2007).
} 
Breton (2009, p. 24): "qualquer questionamento sobre corpo requer antes a construção de seu objeto, a elucidação daquilo que subentende".

Boltanski (2004), por exemplo, realiza um trabalho quanto à cultura corporal, sob a forma clássica da sociologia francesa, ou seja, trazendo os dados empíricos, descrevendo-os e os analisando, tendo como questão de fundo a instrumentalização do corpo. Segundo tal autor, o que une as diferenças nos sujeitos investigados são os hábitos de classe que vão permitir com que o pesquisador agrupe esses agentes em grupos sociais. Para este autor francês, há uma cultura corporal específica para grupos sociais heterogêneos, e isso pode ser observado, por exemplo, nas condutas sexuais, nos comportamentos sanitários, no vestuário e na alimentação. Também as relações médico-paciente não são idênticas nos diversos grupos sociais, pois conforme aumenta a posição na hierarquia social, a percepção sobre o que é agradável e o que é prazer corporal é maior, que pode ser observado nos estratos sociais diversos (partindo dos agricultores, passando pelos operários, pelos assalariados terciário e técnicos assalariados e assim por diante - na configuração da sociologia empírica francesa).

A isso, Boltanski (2004) vai chamar código de boas maneiras corporal: "Porque tal código, profundamente inconsciente, só se exprime, como os códigos linguísticos, através de seus produtos, ou seja, na prática daqueles cuja prática ele rege, só pode ser percebido pela observação, análise e comparação das práticas corporais dos membros dos diferentes grupos sociais [...]”. (BOLTANSKI, 2004, p. 136)

Outro francês, o antropólogo Marcel Mauss, autor do clássico As técnicas corporais ou As técnicas do corpo (MAUSS, 2015) ensaiou sobre como os seres humanos vão se modificando diante das técnicas que se transformam de acordo com as sociedades e os contextos históricos, principalmente em relação aos seus corpos, pois: "[...] O corpo é o primeiro e o mais natural instrumento do homem. Ou, mais exatamente, sem falar de instrumento: o primeiro e o mais natural objeto técnico, e ao mesmo tempo meio técnico, do homem, é seu corpo". (MAUSS, 2015, p. 405)

Essa assimilação de técnicas que se dão no corpo, conforme Mauss (2015), ocorrem também devido à educação, como imitação prestigiosa, em que "A criança, como o adulto, imita atos bem-sucedidos que ela viu ser efetuados por pessoas nas quais confia e que têm autoridade sobre ela”. (MAUSS, 2015, p. 403). A educação também se relaciona à tradição, pois toda técnica é um ato tradicional e eficaz: "[...] Não há técnica nem transmissão se não houver tradição. Eis em que o homem se distingue antes de tudo dos animais: pela transmissão de suas técnicas e muito provavelmente por sua transmissão oral”. (MAUSS, 2015, p. 405).

Assim, Mauss (2015) vai considerar duas variáveis classificatórias que são facilmente identificáveis a partir das técnicas do corpo: a divisão das técnicas corporais entre os sexos (considerando que há uma sociedade dos homens e uma das mulheres); e a variação das técnicas corporais com as idades (crianças utilizam seus corpos de uma forma, adultos e idosos de outra forma). Também vai considerar que é possível se classificar as técnicas corporais em relação ao rendimento (enquanto adestramento humano, o treinamento) e à transmissão da forma das técnicas (os detalhes que envolvem esse conjunto de classificação. 
Outro autor que é central para compreendermos o corpo enquanto território político de sua "educação" é o sociólogo francês Pierre Bourdieu. Bourdieu (2011, p. 185) afirma que "O corpo está no mundo social, mas o mundo social está no corpo (sob forma de hexis)". A hexis é a forma como os habitus foram incorporados, na forma de disposições permanentes, nos corpos dos sujeitos. Assim, podemos pensar que o habitus é "[...] a história encarnada nos corpos" (BOURDIEU, 2011, p. 184).

Detemo-nos, então, àquilo que Bourdieu (2011) considera em específico quanto à noção de habitus e a hexis corporal enquanto possibilidade interpretativa para pensarmos o senso prático, ou as aprendizagens que vamos incorporando e acumulando ao longo de nossas experiências cotidianas - e isso nos permite, obviamente, pensar no contexto da educação e da política quanto à educação do corpo.

Bourdieu (2011) expõe que a noção de habitus tem por função descartar dois erros complementares sobre a questão do sujeito: (1) com a noção de habitus, passamos a compreender as ações humanas não mais como algo meramente mecânico de causas externas; (2) também passamos a descartar a ideia comum de que o agente atua de maneira livre e consciente, ou seja, a desnaturalização do naturalizado:

[...] os agentes sociais são dotados de habitus, inscritos nos corpos pelas experiências passadas: tais sistemas de esquemas de percepção, apreciação e ação permitem tanto operar atos de conhecimento prático, fundados no mapeamento e no reconhecimento de estímulos condicionais e convencionais a que os agentes estão dispostos a reagir, como também engendrar, sem posição explícita de finalidades nem cálculo racional de meios, estratégias adaptadas e incessantemente renovadas, situadas porém nos limites das constrições estruturais de que são o produto e que as definem (BOURDIEU, 2011, p. 169).

É possível, nesse sentido, pensarmos em associações entre o que Bourdieu (2011) aborda quanto ao habitus enquanto corpo histórico e socializado e àquilo que Mauss (2015) explicita diante das técnicas corporais, tendo em vista, como escreve Bourdieu (2011, p. 191), que “[...] o social também se institui nos indivíduos biológicos, existe muito de coletivo em cada indivíduo socializado, entendendo-se por isso propriedades válidas para uma classe inteira de agentes". A chave de interpretação, tanto em um, como em outro autor, está nas práticas, que são visíveis pela decodificação das estruturas objetivas (disposições, habitus) e nas estruturas cognitivas. Para Bourdieu (2011, p. 182), “[...] as condições de sua formação [habitus] são também as condições de sua realização.”

Inegável, portanto, diante do exposto, que o campo da política e o campo da educação se configuram como espaços sociais ricos para ampliarmos as compreensões e reflexões quanto às implicações dessas disposições sociais, culturais, econômicas e históricas nos agentes que vão participando dos contextos pedagógicos de aprendizagem no que se refere à educação do corpo. 


\section{Práticas corporais e política ${ }^{5}$}

O conceito de política pode ser pensado, de forma ampla, como a gestão do comportamento humano. De forma ampla, pois pensar a política enquanto gestão do comportamento significa abarcar em seu conceito questões jurídicas e morais da área do Direito; teorias de governo estatal; discussões filosóficas da arte/ciência de governar; e, também, os comportamentos intersubjetivos intercambiados nos mais diversos contextos culturais. Na tentativa de aproximar o conceito de política aos usos sociais do corpo - via técnicas corporais - entendemos que a gestão do comportamento humano está materialmente inscrita e suportada pelos corpos regulados por regras e valores culturalmente relativos que, em última instância, implicam técnicas corporais que em meio à pluralidade dos seres falantes (massa/população) tentam impor algum tipo de limite para definir comportamentos adequados dentro de uma sociedade organizada para além das vontades individuais (MILNER, 2013).

A partir da modernidade o corpo biológico da anatomia foi se transformando em um corpo técnico e objeto da política na medida em que a racionalidade científica e técnica começaram a ser pensadas para promover o desenvolvimento das forças produtivas da sociedade. A educação dos corpos e da população passa assim a se estruturar a partir dos fundamentos das ciências biomédicas: "Las libertades políticas empiezan y terminan por los cuerpos. Las dictaduras siempre la toman con los cuerpos. Aclaremos: con su anatomía y con su fisiología" (MILNER, 2013, p. 18). Ou como nos diz Canguilhem (1976) a biologia passa a ser um imperativo, mais que um método, uma moral, mais que uma teoria. Desta racionalidade política nasce a biopolítica ${ }^{6}$, isto é, o governo da vida: "A biopolítica diz que o humano se constitui politicamente a partir de uma gestão dos corpos - e que portanto, trata-se de uma política de corporalidade, de corporização, do que faz do corpo e da vida um terreno sobre o qual se estampam normas e formas de vida normativa" (GIORGI, 2016, p. 39).

Os estudos genealógicos do filósofo francês Michel Foucault demonstram de forma minuciosa como o governo da população foi possível por uma política estatal de regulação das práticas cujos corpos passaram a ser vistos sob o viés da anatomia política. Para Foucault (2001) a "anatomia política" é uma "mecânica de poder", que define como se pode ter domínio sobre o corpo dos outros, não simplesmente para que façam o que se quer, mas que operem como se quer, com técnicas segundo a rapidez e eficácia que se determina.

Se pensarmos esta lógica sob a perspectiva educacional vamos perceber que historicamente as instituições educativas estatais sempre utilizaram em seus programas escolares a transmissão de técnicas corporais com a

\footnotetext{
${ }^{5}$ Aqui o conceito de práticas corporais é utilizado em consonância com a noção de técnicas corporais desenvolvido por Mauss (2015) para se reportar aos usos cotidianos do corpo em práticas compartidas socialmente. No campo da Educação Física brasileira foi formulado o conceito de práticas corporais (SILVA; LAZZAROTTI FILHO e ANTUNES, 2014). De maneira resumida, tratar das práticas corporais é identificar a dimensão corporal diante das manifestações culturais; é buscar a superação da fragmentação identificada quanto ao ser humano e sua vida contemporânea com as implicações em seus corpos; é apontar para uma dimensão conceitual como elemento das ciências humanas e sociais que tencionam com a concepção de ciência pautada na objetividade e neutralidade; externam uma preocupação com os significados/sentidos atribuídos às práticas corporais por parte dos sujeitos que as praticam para além de sua utilidade pragmática, dentre outras características. (LAZZAROTTI FILHO et al, 2010).

${ }^{6}$ Para uma abordagem mais ampla sobre o conceito, sugerimos a leitura de Fahri Neto (2008).
} 
finalidade de controlar o corpo individual e o corpo social: "El cuerpo fue objeto de representaciones dirigidas a construir a partir de él un proyeto colectivo"(VALEJO; MIRANDA, 2007, p. 18).

Estas práticas sempre estiveram justificadas por um saber científico imbuídas de um discurso moral, conforme analisam Vallejo e Miranda (2007, p. 17): “[...] el cuerpo era la expresión de un ideal coletivo que servia de espejo público para que el ciudadano común internalice el discurso del poder".

Se dialogarmos aqui com a educação do corpo sob a mirada da Educação Física vamos perceber que ao tratar sobre a engendração dessa disciplina nos currículos escolares brasileiros, esse processo de escolarização ocorreu historicamente a partir de quatro principais movimentos: (1) a influência dos médicos em educar tratos corporais; (2) a influência do movimento higienista brasileiro no século XIX promovendo a escolarização da Educação Física; (3) ampliação da abrangência quanto à formação humana; (4) a Educação Física sendo reduzida às práticas de ginástica e, depois, sistematizada para permitir o ganho da aptidão física. (PAIVA, 2003).

Também poderíamos pensar em outros exemplos não tão explícitos quanto a esses que a Educação Física nos permite visualizar, em relação aos demais componentes curriculares escolares que também operam um certo modo de educação do corpo, ou mesmo enquanto uma subjetivação proporcionada pela instituição escolar como um todo, como descreve Galak (2011):

[...] la escuela es el principal vehículo institucional de transmisión de las maneras o modos correctos de organización, esquematización e inscripción de todos los valores, prácticas, saberes y discursos (con $s u$ ética, política y estética); pero también, y de especial interés para el propósito de esta intervención, es la primordial manera en la que se aprenden los modos en que la (di)visión del mundo se incorpora, se hace cuerpo, carne y natural. Decir que se naturalizan los modos éticos, políticos y estéticos correctos de llevar el cuerpo es decir que se tornan esos conocimientos aprendidos en prácticas cuyo sentido práctico es inefable, inconciente, pre-reflexivo (GALAK, 2011, p. 10).

Frente ao exposto acima, faz-se necessário retomar a importância de se pesquisar o corpo sob as lentes da Educação a fim de pensar as políticas que normatizam os usos do corpo no âmbito educacional com a intenção de desestabilizar as normas impostas por projetos modernos "assassinos". Porque com a modernidade nasceu também o direito de exterminar o outro legitimado pela racionalidade biopolítica que autoriza o cadáver via construção da fobia do outro.

A modernidade criou políticas que justificaram o apagamento de corpos sob a certificação da ciência: os corpos de desaparecidos políticos, o corpo negro, o corpo do índio, o corpo da mulher, o corpo do deficiente, o corpo homossexual, o corpo trans. Os corpos destes grupos podem ser lidos sob as sombras de sua história, sob a escuridão de políticas que os tornaram invisíveis - a modernidade fez "sombras" com suas "luzes". Todos estes são corpos que ficaram de fora da história do Direito, porque esse nunca os alcançou - ou, se pretendeu alcançar, como no caso brasileiro, vimos que vem uma "forte onda" conservadora que a tudo quer destruir em se tratando de minorias societárias, explicitamente durante o processo das eleições presidenciais de 2018. 
E para além de nossas pesquisas em Educação, como podemos pensar o corpo e as práticas/técnicas corporais enquanto conteúdo transversal nas temáticas de nossas disciplinas no contexto das mais variadas disciplinas - seja no âmbito da Educação Básica ou no Ensino Superior?

\begin{abstract}
Pensar la curricularización del cuerpo según la propuesta que aquí se sigue implica concebir no solo las concepciones sociales sobre este, sino también aquellas que se hacen de los sujetos y de la política. Dicho de otro modo, reflexionar acerca de la episteme que encierra la educación institucionalizada del cuerpo en cualquier momento de la historia supone considerar las maneras en que se argumentan las formas como las sociedades se organizan y reproducen a sí mismas. Así como los modos de interpretar a los sujetos involucrados en estas (GALAK, 2017, p. 194).
\end{abstract}

Compreender os corpos via leitura histórica das políticas (mecanismos e instituições) que os fixaram e legitimaram como "inferiores" ou "anormais" é passo importante para desnaturalizar o naturalizado e tirá-los das "sombras" - torná-los visíveis. O corpo como suporte material da política, deve ser o ponto de partida para se pensar uma política pautada na ética e na estética de corpos singulares, de corpos que resistem a uma modernidade que fabrica corpos em série para fazer girar as engrenagens do capitalismo neoliberal.

\title{
4 Considerações finais
}

Pesquisar o corpo enquanto objeto de pesquisa na Educação implica comprometimento político e epistemológico para desnaturalizar práticas que o educam para assumir a posição de mero fantoche utilitário e consumidor a encenar as mitificações feitas pela ciência moderna. A valorização excessiva da ciência e por consequência, da técnica - características fundantes da modernidade - muitas vezes colocam o corpo na condição de sujeito epistêmico prestes a declarar seu "fim" (metafísico) em meio a políticas que justificam sua obsolescência.

Retomando o objetivo deste ensaio que foi o de reflexionar o corpo enquanto objeto de estudo da Educação a partir de suas práticas, interpelando estas a partir da política nas quais elas estão inscritas, sustentamos que definitivamente o corpo só pode ser pensado na sua relação com a política. "Corpo" e "sujeito", em conjunto consonante com a "política", se compõe como que uma rede de nós - enquanto amarra e enquanto plural de eu que constantemente se faz presente em toda investigação que tome por objeto o corpo (GALAK, 2014). Desta forma encerramos nosso ensaio reiterando o que escrevemos como palavras iniciais: o corpo não existe fora da política, fora da palavra!

\section{Referências}

BÁRTOLO, José. Corpo e sentido: estudos intersemióticos. Portugal/Covilhã: Livros LabCom, 2007. 
BOLTANSKI, Luc. As classes sociais e o corpo. 3ª ed. São Paulo: Paz e Terra, 2004.

BOURDIEU, Pierre. O conhecimento pelo corpo. In: BOURDIEU, Pierre. Meditações pascalianas. Tradução Sérgio Miceli. Rio de Janeiro: Bertrand Brasil, 2011, p. 157-198.

CANGUILHEM, Georges. El conocimiento de la vida. Barcelona: Anagrama. 1976.

CRISORIO, Ricardo. Actividad(es) física(s) versus prácticas corporales. In: GALAK, Eduardo; GAMBAROTTA, Emiliano. (orgs). Cuerpo, Educación, Política: tensiones epistémicas, históricas y prácticas, Buenos Aires: Biblos, 2015, p. 21-39.

FAHRI NETO, Leon. Biopolítica como tecnologia de poder. Interthesis, Florianópolis, v. 5, p. 47-65, jan./jul. 2008.

FOUCAULT, Michel. Vigiar e Punir: história da violência nas prisões. 22. ed. Petrópolis, RJ: Vozes, 2001.

GALAK, Eduardo. La curricularización del cuerpo. In: CRISORIO, Ricardo; ESCUDERO, Carolina (orgs.). Educación del cuerpo: currículum, sujeto y saber, Argentina/La Plata: Editora da Universidad Nacional de La Plata, 2017, p. 191-198.

GALAK, Eduardo. Construir el cuerpo: cuatro consideraciones epistemo-metodológicas y tres metáforas para pensar el objeto de estudio 'cuerpo'. Poiésis: Revista do Programa de Pós-Graduação em Educação da UNIVALI. Tubarão/SC, v. 8, n. 14, p. 348-364, jul./dez. 2014.

GALAK, Eduardo. Meditações bourdieuanas: uma abordagem sobre o problema da educação do corpo na lógica epistemológica do Pierre Bourdieu. In: CONGRESSO BRASILEIRO DE CIÊNCIAS DO ESPORTE; CONGRESSO INTERNACIONAL DE CIÊNCIAS DO ESPORTE, 17;4, 2011, Porto Alegre. Anais... Porto Alegre: CBCE, 2011, 12 p.

GIORGI, Gabriel. Formas comuns: animalidade, literatura, biopolítica. Tradução de Carlos Nougué. Rio de Janeiro: Rocco, 2016.

LAZZAROTTI FILHO, Ari et al. O termo práticas corporais na literatura científica brasileira e sua repercussão no campo da Educação Física. Movimento, Porto Alegre, v. 16, n. 1, 2010, p. 11-29.

LE BRETON, David. A sociologia do corpo. Tradução de Sonia M. S. Fuhrmann. 3. ed. Petrópolis: Vozes, 2009.

LUZ, Madel T. Novos saberes e práticas em saúde coletiva: estudo sobre racionalidades médicas e atividades corporais. $3^{\text {a }}$. Ed. São Paulo: Hucitec, 2007.

MAUSS, Marcel. As Técnicas Corporais. In MAUSS, Marcel. Sociologia e Antropologia. $2^{\mathrm{a}}$ ed. Tradução Paulo Neves. São Paulo: COSAC NAIFY, 2015, p. 397-420.

MILNER, Jean-Claude. Por una política de los seres hablantes: breve tratado político II. - 1 ed. - Olivos: Grama Ediciones, 2013.

PAIVA, Fernanda. Constituição do campo da Educação Física no Brasil: ponderações acerca de sua especificidade e autonomia. In: BRACHT, Valter; CRISORIO, Ricardo (orgs.). A Educação Física no Brasil e na Argentina: identidade, desafios e perspectivas. Campinas/SP: Autores Associados; Rio de Janeiro/RJ: PROSUL, 2003, p. 6380.

PRECIADO, Beatriz. Manifesto contrassexual. Tradução de Maria Paula Gurgel Ribeiro. São Paulo: n-1 Edições, 2014. 
SILVA, Ana Márcia; LAZZAROTTI FILHO, Ari; ANTUNES, Priscila de Césaro. Práticas corporais. In: GONZÁLEZ, Fernando Jaime; FENSTERSEIFER, Paulo Evaldo. Dicionário Crítico de Educação Física. $3^{\mathrm{a}}$ ed. rev. ampl. Ijuí: Unijuí, 2014.

VALLEJO, Gustavo; MIRANDA, Marisa. Apresentação: cuerpo social y cuerpo individual. In: VALLEJO, Gustavo; MIRANDA, Marisa (orgs.). Políticas del cuerpo: estrategias modernas de normalización del indivíduo y la sociedad. Buenos Aires: Siglo XXI Editora, 2007, p. 15-22.

VELHO, Gilberto. Subjetividade e sociedade: uma experiência de geração. $4^{\mathrm{a}}$. ed. Rio de Janeiro: Jorge Zahar Editor, 2006.

ZOBOLI, Fabio. Educação do corpo e política. In: RODRIGUES, Ana Cláudia da Silva; SEVERO, José Leonardo Rolim de Lima. Diálogos interdisciplinares e temas emergentes na produção do conhecimento em Educação. João Pessoa: Editora do CCTA, 2018, p.365-374.

\section{Como citar este artigo}

Zoboli, Fabio; Mezzaroba, Cristiano. Corpo e política: Notas sobre a educação do corpo. Revista Kinesis, Santa Maria, v. 37, p. 01-11, 2019. 